\title{
Application of in-House Method for Determination of Radium Isotopes in Environmental Samples Using the Liquid Scintillation Counting Technique
}

\author{
Nik Azlin Nik Ariffin ${ }^{*}$, Zal Uyun Wan Mahmood ${ }^{2}$, Che Abd Rahim Mohamed ${ }^{3}$ \\ ${ }^{1}$ School of Environmental \& Natural Resources Sciences, Faculty of Science and Technology, Universiti Kebangsaan Malaysia, \\ Bangi, Selangor, Malaysia; ${ }^{2}$ Radiochemistry and Environment Group, Malaysia Nuclear Agency, Bangi, Selangor, Malaysia; \\ ${ }^{3}$ Marine Ecosystem Research Centre (EKOMAR), Universiti Kebangsaan Malaysia, Bangi, Selangor, Malaysia. \\ Email: "niq_lynn@yahoo.com; azlin_ariffin@salam.uitm.edu.my
}

Received August 25 $5^{\text {th }}, 2011$; revised September 19 ${ }^{\text {th }}, 2011$; accepted September $28^{\text {th }}, 2011$.

\begin{abstract}
A method for determination of ${ }^{226} \mathrm{Ra}$ and ${ }^{228} \mathrm{Ra}$ in environmental samples using the $\alpha-\beta$ coincidence liquid scintillation counting (LSC) has been developed. Radium were preconcentrated from environmental samples by coprecipitation with $\mathrm{BaSO}_{4}$, then purified from others radionuclide interferences using the cation column exchange (Bio-Rad AG $50 \mathrm{~W}-\mathrm{X} 4$ resin with 200 - 400 mesh size and $H^{+}$form) and operating in warm temperature which is between $70^{\circ} \mathrm{C}-80^{\circ} \mathrm{C}$. Then, the $\mathrm{Ba}(\mathrm{Ra}) \mathrm{SO}_{4}$ precipitate was filtered through the Millipore filter paper, dried and weighed to calculate chemical yield. The activity concentration of radium isotopes in mixture of liquid scintillation cocktails were measured using LSC after being stored for over 21 days to allow the growth of the progeny nuclides. The method has been validated with a certified reference material supplied by the International Atomic Energy Agency and reliable results were obtained. The radiochemical yields for radium were $59 \%$ - 90\% and recovery was $97 \%$ and $80 \%$ for ${ }^{226} R a$ and ${ }^{228} R$ a, respectively. Sixteen seawater and fish flesh samples collected in Kapar coastal water have been analyzed with the developed method. The obtained radium activity concentrations in seawater were in the range of $2.08 \pm 0.82 \mathrm{mBq} / \mathrm{L}$ to $3.69 \pm 1.29 \mathrm{mBq} / \mathrm{L}$ for ${ }^{226} \mathrm{Ra}$ and $6.01 \pm 3.05 \mathrm{mBq} / \mathrm{L}$ to $17.07 \pm 6.62 \mathrm{mBq} / \mathrm{L}$ for ${ }^{228} \mathrm{Ra}$. Meanwhile, the activity concentrations of ${ }^{226} \mathrm{Ra}$ and ${ }^{228} \mathrm{Ra}$ in fish flesh were in the range of $11.82 \pm 5.23-16.53 \pm 6.53 \mathrm{~Bq} / \mathrm{kg}$ dry wt. and $43.52 \pm 16.34-53.57 \pm 19.86$ $B q / k g$ dry wt., respectively.
\end{abstract}

Keywords: ${ }^{226} \mathrm{Ra},{ }^{228} \mathrm{Ra}$, Environmental Samples, Chemical Yield, Liquid Scintillation Counting

\section{Introduction}

Radium is commonly measured using a various analytical procedures and equipments. The most common methods for determining radium isotopes are alpha spectrometry [1,2], gamma spectrometry [3-5], Cerenkov counting [6] and liquid scintillation counting [7-14]. Alpha spectrometry is the most sensitive technique and allows simultaneous measurement of $\alpha$-emitting radium isotopes but it is difficult to isolate the radium from other alkaline earth metals [15-17]. Meanwhile $\gamma$-emission is relatively low due to low counting sensitively and liable to interference from ${ }^{235} \mathrm{U}$ [17-19]. But the liquid scintillation counting (LSC) provides detection efficiency up to $100 \%$ for unquenched samples and intrinsically high background count rate compared with other counting methods [20].

The radionuclides of ${ }^{226} \mathrm{Ra}$ and ${ }^{228} \mathrm{Ra}$ can be measured in environmental samples using a range of techniques with offers a number of advantages such as time saving and simplicity [21]. Through LSC methods also, radium in mineral waters [22], contaminated rivers [8] and phosphogypsum samples [23] can be measured. The aim of the study is to develop a simple method for determination of ${ }^{226} \mathrm{Ra}$ and ${ }^{228} \mathrm{Ra}$ in environmental samples using the $\alpha-\beta$ coincidence LSC. The present method is applied to some environmental samples and certified reference material prepared by International Atomic Energy Agency (IAEA) for procedure validation.

\section{Experimental}

The complete procedure of isolation and determination of 
${ }^{226} \mathrm{Ra}$ and ${ }^{228} \mathrm{Ra}$ in natural samples was tested in the following IAEA reference materials: IAEA 300 (Radionuclides in Baltic Sea sediment) and IAEA-315 (Radionuclides in marine sediment). Then, this procedure with minor modification was used to determine activity concentration of ${ }^{226} \mathrm{Ra}$ and ${ }^{228} \mathrm{Ra}$ in seawater and fish samples collected at Kapar coastal area which located at Straits of Malacca, Malaysia (Figure 1).

\subsection{Chemicals and Reagents}

The cation exchanger Bio-Rad AG $50 \mathrm{~W}-\mathrm{X} 4$ resin with size $200-400$ mesh and $\mathrm{H}^{+}$form was used to purify ${ }^{226} \mathrm{Ra}$ and ${ }^{228} \mathrm{Ra}$ from other radionuclide interferences. All reagents of analytical grade were used unless otherwise stated. High quality of instage ${ }^{\circledR}$ XF and Ultimate ${ }^{\mathrm{TM}}$ Gold AB supplied by Perkin Elmer also was used.

\subsection{Instrumentation}

A Perkin Elmer-Wallac $1414 \alpha-\beta$ coincidence Liquid Scintillation Analyzer connected to compatible personal computer was used. High quality and performance of 20 $\mathrm{mL}$ glass vials were used in this study.

\subsection{Analytical Procedure}

\subsubsection{Solid Sample (Reference Materials and Fish Flesh)}

All the solid samples were dried in an oven at $60^{\circ} \mathrm{C}$ until a constant weight prior to further analysis. Briefly, about $0.5 \mathrm{~g}$ solid sample was weighed and $25 \mathrm{mg} / \mathrm{ml}$ of $\mathrm{Ba}^{2+}$ carrier was added in the sample. Then, the samples were digested with $10 \mathrm{ml}$ of each $\mathrm{HNO}_{3}, \mathrm{HClO}_{4}$, HF concentrated acid and a few drops of $\mathrm{H}_{2} \mathrm{O}_{2}$ on hot plate until dryness. After digestion, samples were added with $5 \mathrm{~mL}$ of concentrated $\mathrm{HNO}_{3}$ and a few drops of $\mathrm{H}_{2} \mathrm{O}_{2}$, then dried on hot plate. The sample residue containing radium isotopes was re-dissolved with $20 \mathrm{ml}$ of $1 \% \mathrm{HClO}_{4}$ and kept warm on hot plate for 1 hour - 2 hours prior to pass through the column.

\subsubsection{Solution Sample (Seawater)}

About $12 \mathrm{~L}$ of seawater samples were collected using Van Dorn water sampler and the in-situ parameters such as salinity, conductivity, $\mathrm{pH}, \mathrm{DO}$ were also measured using the calibrated portable meter (Model: YSI-SCT 6810). After that, seawater samples were filtered, transferred into bucket and acidified with concentrated $\mathrm{HNO}_{3}$ to $\mathrm{pH}$ 2. Then, $1 \mathrm{ml}$ of barium and ferum carrier solutions $(25 \mathrm{mg} / \mathrm{ml})$ and $10 \mathrm{~g}$ of $\mathrm{Na}_{2} \mathrm{CO}_{3}$ were added into the seawater samples. The samples were stirred vigorously after added $20 \mathrm{ml}$ of ammonia solution to reach $\mathrm{pH} 10$. Then, the samples were put aside for overnight to settle down the precipitate that appeared after a few minutes added with ammonia solution. The liquid was then poured out and discarded. Meanwhile, the precipitate was siphoned out into cleaned beaker. The precipitate with the rest of liquid was centrifuged for 10 minutes at 2500 rpm to separate both phase. The precipitate containing radium isotopes was re-dissolved with $20 \mathrm{ml}$ of $1 \%$ $\mathrm{HClO}_{4}$ and kept warm on hot plate for 1 hour - 2 hours prior to pass through the column.

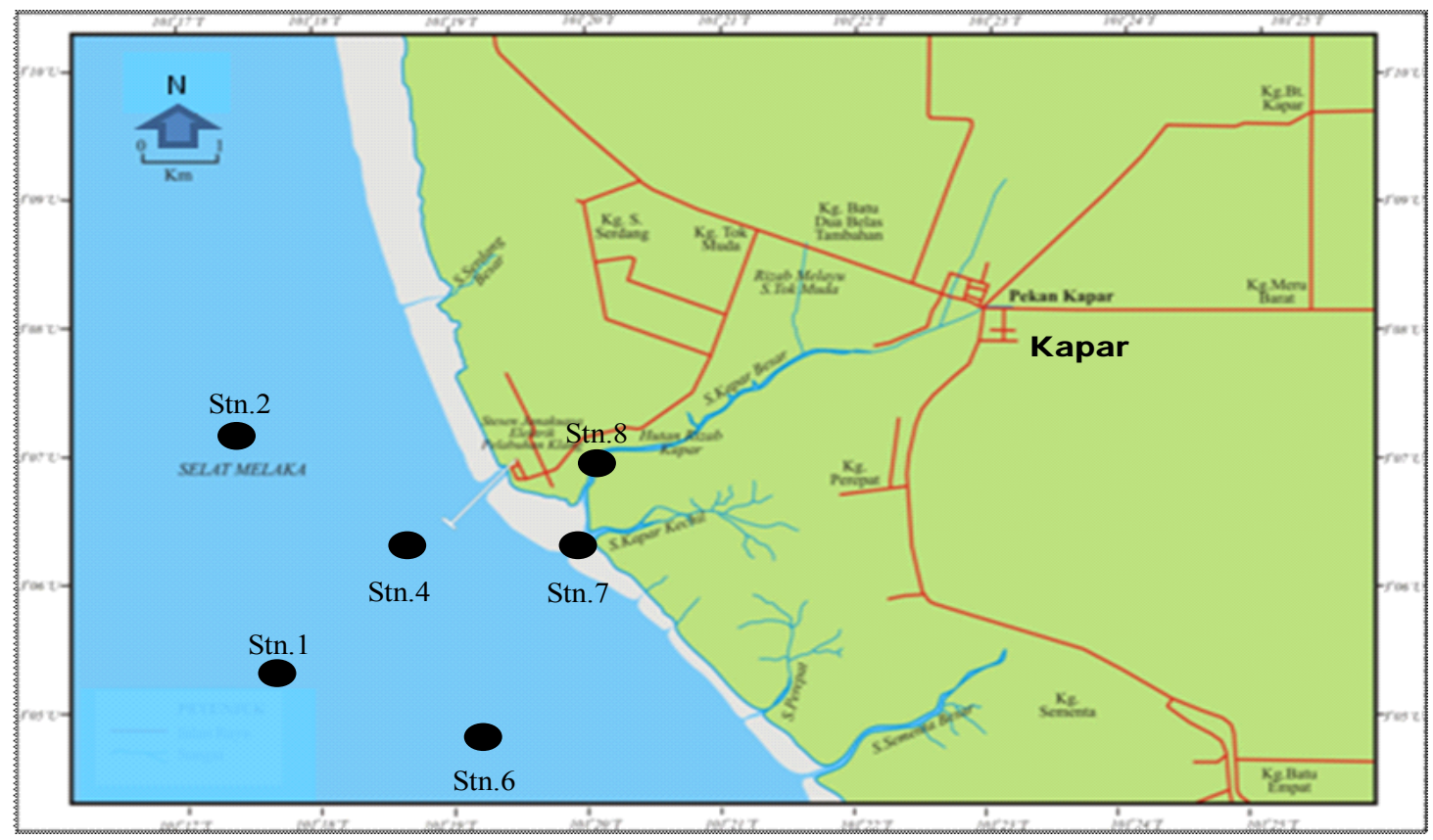

Figure 1. Sampling sites of water samples at Kapar coastal area. 


\subsubsection{Radiochemical Separation Using Cation Ex- change Resin}

The above warmed solution samples were passed through into the cation exchange column resin ( $35 \mathrm{ml}$ of Bio-Rad AG $50 \mathrm{~W}-\mathrm{X} 4 ; 200$ - 400 mesh; $\mathrm{H}^{+}$form) under warm condition at $70^{\circ} \mathrm{C}$ which pre-conditioned with $1 \% \mathrm{HClO}_{4}$ prior to use. Then, all solution were collected in beaker and discarded. In the first stage, about $200 \mathrm{ml}$ of $1 \mathrm{M}$ $\mathrm{HCl}$ were added into the column; the aqueous solutions were collected into new beaker and kept it at safe place for lead, uranium and others radionuclide analysis purposes. During second stage, the column were added with $200 \mathrm{ml}$ of $2 \mathrm{M} \mathrm{HCl}$ and aqueous solution which contained radium isotopes were collected into cleaned beaker.

The aqueous samples were evaporated nearly dryness and kept cool for a while. About $20 \mathrm{ml}$ of $0.5 \mathrm{M} \mathrm{HCl}$ and $1 \mathrm{ml}$ of concentrated $\mathrm{H}_{2} \mathrm{SO}_{4}$ were continue added into the residue for making white precipitate of $\mathrm{Ba}(\mathrm{Ra}) \mathrm{SO}_{4}$. The precipitates were then filtered using $25 \mathrm{~mm}$ diameter of $0.45 \mu \mathrm{m}$ pore size Millipore filter paper, dried and weighed for calculating chemical yield. The dried precipitates together with the filter paper were then transferred into a $20 \mathrm{ml}$ glass vial followed by adding $8 \mathrm{ml}$ of distilled water, $4 \mathrm{ml}$ of Instagel ${ }^{\circledR} \mathrm{XF}$ and $8 \mathrm{ml}$ of Ultimate ${ }^{\mathrm{TM}}$ Gold $\mathrm{AB}$. After well mixing using ultrasonic cleaner, the vials were stored for over 21 days to allow the growth of the progeny nuclides $[9,10,12]$. Finally the vials were counting using the $\alpha-\beta$ coincidence liquid scintillation counter (LSC) for one hour. The flowchart of detail analytical procedure for separation of radium is illustrated in Figure 2.

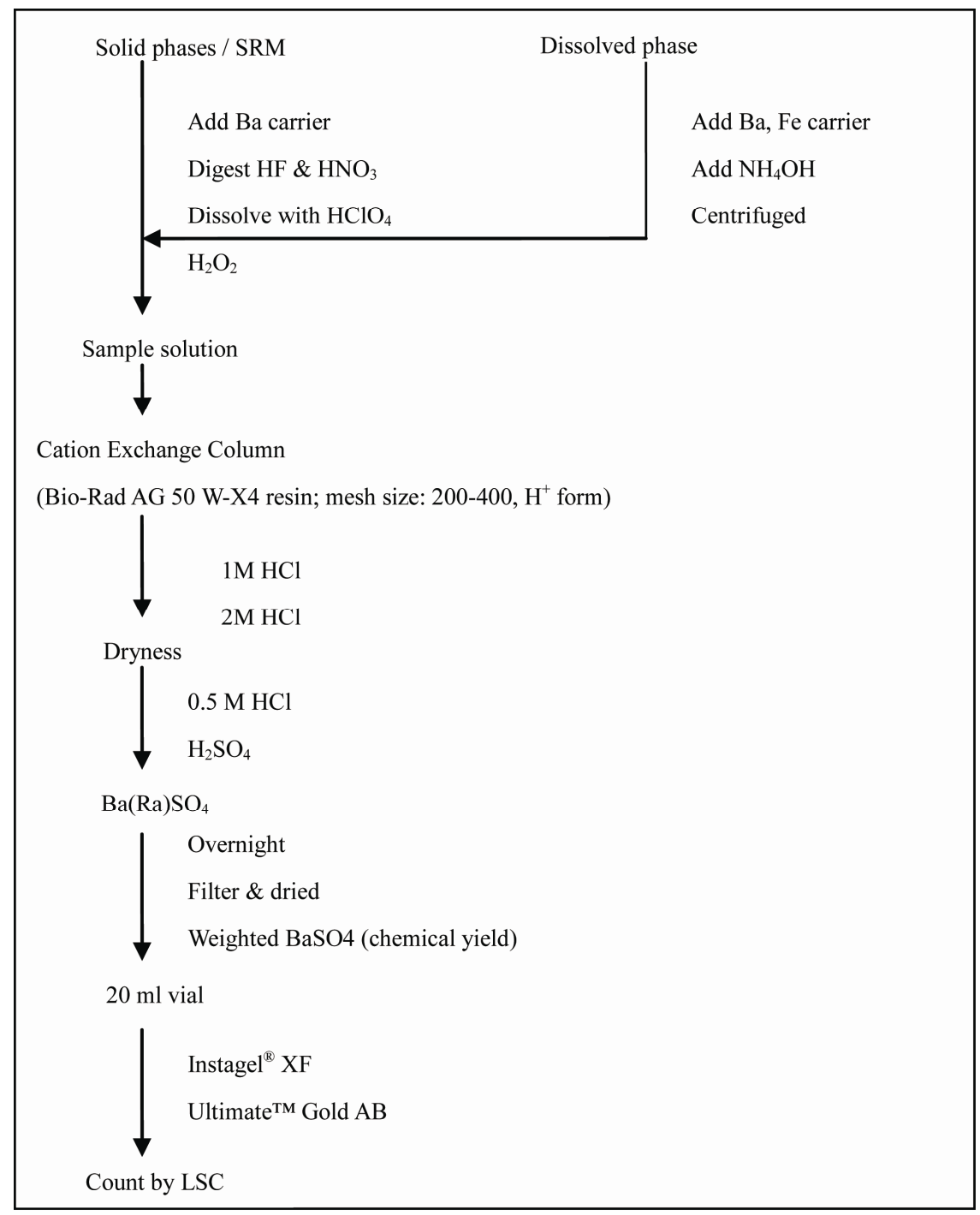

Figure 2. Flow chart of separation procedure and preparation for radium isotopes. 


\subsection{Preparation of Blank and Standard Solution}

A $8 \mathrm{ml}$ of distilled water, $4 \mathrm{ml}$ of Instage ${ }^{\circledR} \mathrm{XF}$ and $8 \mathrm{ml}$ of Ultimate ${ }^{\mathrm{TM}}$ Gold $\mathrm{AB}$ were mixed into the vial and were measured using $\alpha-\beta$ coincidence liquid scintillation counter for one hour as a blank sample. Meanwhile, $1 \mathrm{ml}$ of the standard solution of ${ }^{226} \mathrm{Ra}(20 \mathrm{dpm} / \mathrm{ml})$ was prepared then followed the same procedure as for blank sample.

\subsection{Calculation of Activity Concentration for Radium}

It is a simple method based on the $\alpha$-counting of precipitate containing radium, generally $\mathrm{Ba}(\mathrm{Ra}) \mathrm{SO}_{4}$. For determining ${ }^{226} \mathrm{Ra}$ in environmental samples, it would be better to count the samples after one month of growth for secular equilibrium in half life. Using the $\alpha$-rays by LSC the measurement of ${ }^{226} \mathrm{Ra}$ activity can be calculated as Equation (1):

$$
\mathrm{A}\left({ }^{226} \mathrm{Ra}\right)=\left[\mathrm{cpm}{ }^{226} \mathrm{Ra}\right] /\left[\mathrm{Y} \times \mathrm{E}^{226}{ }_{\mathrm{Ra}}\right]
$$

where $\mathrm{A}\left({ }^{226} \mathrm{Ra}\right)$ is the activity of ${ }^{226} \mathrm{Ra}(\mathrm{dpm}), \mathrm{cpm}{ }^{226} \mathrm{Ra}$ is the count of ${ }^{226} \mathrm{Ra}$ activity per minute, $\mathrm{Y}$ is the yield, $\mathrm{E}_{226 \mathrm{Ra}}$ is the efficiency of ${ }^{226} \mathrm{Ra}$ activity, $\lambda$ is the decay constant of ${ }^{222} \mathrm{Rn}$ (day) and $\mathrm{t}$ is the time start from separation of $\mathrm{Ba}(\mathrm{Ra})$ until counting (day). The ${ }^{228} \mathrm{Ra}$ activity was calculated from the equation 2 [24]:

$$
\mathrm{A}\left({ }^{228} \mathrm{Ra}\right)=\frac{\left(\mathrm{cpm}^{228} \mathrm{Ra}\right)-\left(\mathrm{Y} \times \mathrm{E}_{\mathrm{Ra}}^{226} \times \mathrm{A}_{\mathrm{Ra}}^{226}\right)}{\mathrm{Y} \times \mathrm{E}_{\mathrm{Ra}}^{228}}
$$

where $\mathrm{A}\left({ }^{228} \mathrm{Ra}\right)$ is the activity of ${ }^{228} \mathrm{Ra}(\mathrm{dpm}), \mathrm{cpm}{ }^{228} \mathrm{Ra}$ is the count of ${ }^{228} \mathrm{Ra}$ activity per minute, $\mathrm{Y}$ is the yield, $\mathrm{E}^{226} \mathrm{Ra}$ is the efficiency of ${ }^{226} \mathrm{Ra}$ activity, $\mathrm{E}_{\mathrm{Ra}}^{228}$ is the efficiency of ${ }^{228} \mathrm{Ra}$ activity, $\mathrm{A}\left({ }^{226} \mathrm{Ra}\right)$ is the activity of ${ }^{226} \mathrm{Ra}$ (dpm), $\lambda$ is the decay constant of ${ }^{222} \mathrm{Rn}$ (day) and $t$ is the time start from purification of $\mathrm{Ba}(\mathrm{Ra})$ until counting (day).

\section{Results and Discussion}

Activity concentrations of ${ }^{226} \mathrm{Ra}$ and ${ }^{228} \mathrm{Ra}$ in certified reference materials and seawater were measured simultaneously by LSC after standing more than 21 days to reach the secular equilibrium between parents and its daughters. However, the whole procedure for the separation of radium started from sample preparation to column design taken 1 to 3 days. The reported uncertainty for individual analysis is $1 \sigma$, derived from uncertainties associated of some parameters such as the counting and weight statistics of the sample, blank, standard solution etc. The analytical results of those activity concentrations with uncertainties and the radiochemical yield are listed in Tables 1-2.

\subsection{Quality Control}

The use of certified reference materials containing the radionuclide at known concentration and composition is one of the most appropriate tests to validate methods and the performance of the analysts. For this purpose, it is desirable to have included a certified reference material that matches the sample as closely as possible with respect to its matrix and the concentrations of the constituents of interest to demonstrate the reproducibility and/or accuracy of the method. Unfortunately, however, the certified reference material as mineral and environmental water is not available, and so the IAEA-300 (Radionuclides in Baltic Sea sediment) and IAEA-315 (Radionuclides in marine sediment) reference materials supplied by the IAEA have to be selected to check statisticcally whether the method is sufficiently precise and unbiased [25].

In order to verify the procedures, five sets of each reference materials were used and the results of ${ }^{226} \mathrm{Ra}$ and ${ }^{228} \mathrm{Ra}$ activity concentration in each reference materials as well as the obtained chemical yield and recovery of radium isotopes are presented in Table 1. In comparing the results with the recommended values of ${ }^{226} \mathrm{Ra}$ and ${ }^{228} \mathrm{Ra}$ activity concentration, the agreement is considered to be satisfactory. The results showed that the mean ${ }^{226} \mathrm{Ra}$ and ${ }^{228} \mathrm{Ra}$ activity concentration in IAEA-300 were 54.74 $\mathrm{Bq} / \mathrm{kg}$ dry wt. (information value: $56.5 \mathrm{~Bq} / \mathrm{kg}$ dry wt.) and $49.78 \mathrm{~Bq} / \mathrm{kg}$ dry wt. (certified value : $61.6 \mathrm{~Bq} / \mathrm{kg}$ dry wt.; $59.0 \mathrm{~Bq} / \mathrm{kg}$ - $63.9 \mathrm{~Bq} / \mathrm{kg}$ dry wt.), respectively. Meanwhile, the mean ${ }^{226} \mathrm{Ra}$ and ${ }^{228} \mathrm{Ra}$ activity concentration in IAEA-315 were $11.00 \mathrm{~Bq} / \mathrm{kg}$ dry wt. (certified value: $13.86 \mathrm{~Bq} / \mathrm{kg}$ dry wt.; $13.0 \mathrm{~Bq} / \mathrm{kg}-14.6 \mathrm{~Bq} / \mathrm{kg}$ dry wt.) and $23.66 \mathrm{~Bq} / \mathrm{kg}$ dry wt. (certified value: $26.7 \mathrm{~Bq} / \mathrm{kg}$ dry wt.; $25.3 \mathrm{~Bq} / \mathrm{kg}-28.0 \mathrm{~Bq} / \mathrm{kg}$ dry wt.), respectively. Although, those values obtained were not in the range of the recommended certify value at $95 \%$ confidence interval, but their recoveries were over $80 \%$ and chemical yields were $59 \%$ and $96 \%$ for IAEA-300 and IAEA-315, respectively. Additionally, these results showed that the chemical yield of radium was not significantly influence the accuracy of radium determination in the IAEA reference materials.

The precision and accuracy were evaluated by the term of relative standard deviations and relative error, respectively [25]. The relative standard deviation is also widely used in analytical chemistry to express the repeatability of an assay, where it is derived from the ratio of standard deviation and mean value of radium concentration. Meanwhile, the relative error is the difference between the experimental means and recommended values of radium concentrations. Refer to the statistical analyses given in Table 1 confirmed that the relative standard deviation 
Table 1. ${ }^{226}$ Ra and ${ }^{228}$ Ra activity concentrations (in Bq· $\mathrm{kg}^{-1}$ dry weight) in the reference material IAEA-300 and IAEA-315.

\begin{tabular}{|c|c|c|c|c|c|c|c|c|}
\hline \multirow{2}{*}{ Reference material } & \multirow{2}{*}{$\begin{array}{l}\text { Sample } \\
\text { code }\end{array}$} & \multicolumn{2}{|c|}{$\begin{array}{l}\text { Certified value } \\
\quad(\mathrm{Bq} / \mathrm{kg})\end{array}$} & \multicolumn{2}{|c|}{ Experimental value (Bq/kg) } & \multirow[t]{2}{*}{$\begin{array}{l}\text { Chemical } \\
\text { yield (\%) }\end{array}$} & \multicolumn{2}{|c|}{$\begin{array}{l}\text { Recovery } \\
(\%)\end{array}$} \\
\hline & & ${ }^{226} \mathrm{Ra}$ & ${ }^{228} \mathrm{Ra}$ & ${ }^{226} \mathrm{Ra}$ & ${ }^{228} \mathrm{Ra}$ & & ${ }^{226} \mathrm{Ra}$ & ${ }^{228} \mathrm{Ra}$ \\
\hline & (1) & & & $56.69 \pm 11.54$ & $48.36 \pm 11.46$ & 56.81 & 100.34 & 78.51 \\
\hline & (2) & & & $60.08 \pm 11.90$ & $51.01 \pm 11.76$ & 55.98 & 106.34 & 82.81 \\
\hline IAEA-300 & (3) & $56.5^{*}$ & 61.6 & $50.86 \pm 10.37$ & $53.64 \pm 11.10$ & 63.14 & 90.02 & 87.08 \\
\hline \multirow[t]{2}{*}{ (Baltic Sea sediment) } & (4) & & $(59.0-63.9)$ & $50.89 \pm 10.64$ & $48.42 \pm 10.98$ & 60.66 & 90.07 & 78.60 \\
\hline & (5) & & & $55.16 \pm 11.06$ & $47.65 \pm 11.01$ & 59.88 & 97.63 & 77.35 \\
\hline Mean & & & & 54.74 & 49.78 & 59.29 & 96.88 & 80.87 \\
\hline Standard deviation & & & & 3.95 & 2.49 & & & \\
\hline Relative error (\%) & & & & 3.12 & 19.13 & & & \\
\hline \multirow[t]{3}{*}{$\begin{array}{c}\text { Relative standard deviation } \\
(\%)\end{array}$} & & & & 7.21 & 5.00 & & & \\
\hline & (1) & & & $11.79 \pm 3.91$ & $25.90 \pm 8.79$ & 96.58 & 85.43 & 97.00 \\
\hline & (2) & & & $11.20 \pm 3.87$ & $21.98 \pm 8.25$ & 95.96 & 81.16 & 82.32 \\
\hline IAEA-315 & (3) & 13.8 & 26.7 & $10.30 \pm 3.83$ & $24.66 \pm 8.72$ & 94.76 & 74.64 & 92.36 \\
\hline \multirow[t]{2}{*}{ (Marine sediment) } & (4) & $(13.0-14.6)$ & $(25.3-28.0)$ & $10.90 \pm 3.78$ & $21.76 \pm 8.08$ & 98.13 & 78.99 & 81.50 \\
\hline & (5) & & & $10.83 \pm 3.81$ & $23.98 \pm 8.48$ & 97.26 & 78.48 & 89.81 \\
\hline Mean & & & & 11.00 & 23.66 & 96.54 & 79.74 & 88.60 \\
\hline Standard deviation & & & & 0.55 & 1.77 & & & \\
\hline Relative error (\%) & & & & 20.26 & 11.40 & & & \\
\hline $\begin{array}{l}\text { Relative standard deviation } \\
(\%)\end{array}$ & & & & 4.96 & 7.49 & & & \\
\hline
\end{tabular}

Note: *Information value back correction for IAEA-300 (1st January 1993) and IAEA-315 (1st January 1993).

(RSD) for IAEA-300 is $7.21 \%$ for ${ }^{226} \mathrm{Ra}$ and $5 \%$ for ${ }^{228} \mathrm{Ra}$ and IAEA-315 is $4.96 \%$ for ${ }^{226} \mathrm{Ra}$ and $7.49 \%$ for ${ }^{228} \mathrm{Ra}$. Meanwhile, the relative error (RE) for IAEA-300 is $3.12 \%$ for ${ }^{226} \mathrm{Ra}$ and $19.13 \%$ for ${ }^{228} \mathrm{Ra}$ and IAEA-315 is $20.26 \%$ for ${ }^{226} \mathrm{Ra}$ and $11.40 \%$ for ${ }^{228} \mathrm{Ra}$. These variations RSD and RE might be due to large quantity of other radionuclide interferences in the samples which probably contributed to the lower chemical yield of radium, especially in IAEA-300. In this case also related to the lower activity levels of ${ }^{226} \mathrm{Ra}$ and ${ }^{228} \mathrm{Ra}$ in environmental samples which difficult to measure. For this reason, there has been much interest in development of improved methods for its determination in variety types of samples. Generally, the determination of ${ }^{226} \mathrm{Ra}$ and ${ }^{228} \mathrm{Ra}$ is performed by $\alpha$-rays and $\beta$-rays, respectively [26]. On the other hand, the proper design of the column, column dimensions, the quantity of exchange resin and working condition also necessary to be taken account as high a chemical yield of radium as possible.

\subsection{Application to Seawater and Fish Flesh Sample}

An achievable lower limit of detection is mainly depending on background of the counter used for meas- 
urements, time of counting, counting efficiency and chemical yield. With a low lever counter with background of $0.203 \mathrm{cpm}$ for IAEA-300 and $0.257 \mathrm{cpm}$ for IAEA-315, counting time of 60 minutes, counting efficiency of $10 \%$ and chemical yield of $59.29 \%$ for IAEA-300 and $96.54 \%$ for IAEA-315. Thus, the lower limit of detections (LLD) level for IAEA-300 and IAEA-315 were about $0.1 \mathrm{~Bq} / \mathrm{sample}$ and $0.11 \mathrm{~Bq} / \mathrm{sam}$ ple, respectively. Meanwhile, the detection limits were about $0.59 \mathrm{~Bq}$ and $0.41 \mathrm{~Bq}$ in respectively for IAEA-300 and IAEA-315.

This method has been applied to determine the activity concentrations of ${ }^{226} \mathrm{Ra}$ and ${ }^{228} \mathrm{Ra}$ in seawater and fish flesh sample from Kapar coastal water. The mean radiochemical yields of radium in seawater and fish flesh are $64 \%$ and $75 \%$, respectively. The activity concentrations of radium isotopes in seawater were varied from $2.08 \pm$ $0.82 \mathrm{mBq} / \mathrm{L}$ to $3.69 \pm 1.29 \mathrm{mBq} / \mathrm{L}$ for ${ }^{226} \mathrm{Ra}$ and $6.01 \pm$ $3.05 \mathrm{mBq} / \mathrm{L}$ to $17.07 \pm 6.62 \mathrm{mBq} / \mathrm{L}$ for ${ }^{228} \mathrm{Ra}$. Meanwhile, the activity concentrations of ${ }^{226} \mathrm{Ra}$ and ${ }^{228} \mathrm{Ra}$ in fish flesh were in the range of $11.82 \pm 5.23-16.53 \pm 6.53 \mathrm{~Bq} / \mathrm{kg}$ dry wt. and $43.52 \pm 16.34-53.57 \pm 19.86 \mathrm{~Bq} / \mathrm{kg}$ dry wt., respectively (Figure 3).

The activities of radium isotopes in seawater are almost similar especially in west Peninsular Malaysia and however, found to be relatively low level than other seawater sampled elsewhere in the Malacca Straits and world oceans are listed in Table 2. This means that the activity of radium with LSC was successful using cation exchange column in developing method.
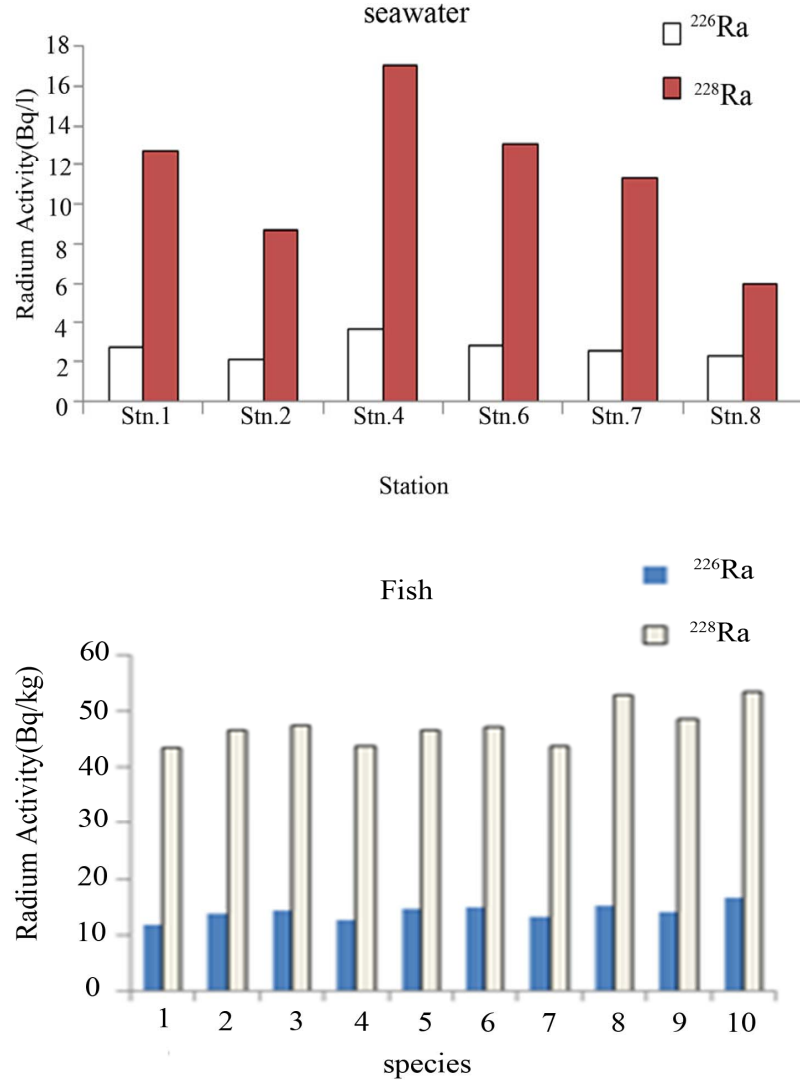

Figure 3. Activity concentrations of radium in seawater and fish flesh samples measured during this study.

Table 2. The activity of ${ }^{226} \mathrm{Ra}$ and ${ }^{228} \mathrm{Ra}$ in sea water sample reported at various locations.

\begin{tabular}{|c|c|c|c|c|}
\hline Country & Locations & ${ }^{226} \mathrm{Ra}(\mathrm{mBq} / \mathrm{L})$ & ${ }^{228} \mathrm{Ra}(\mathrm{mBq} / \mathrm{L})$ & Reference \\
\hline \multirow{6}{*}{ Malaysia } & Kapar, Selangor & $2.08-3.69$ & $6.01-17.07$ & This study \\
\hline & Pulau Redang, Terengganu & $2.08-12.43$ & $5.92-33.53$ & {$[27]$} \\
\hline & Bagan Lalang, Selangor & $1.09-7.14$ & $5.22-218.5$ & {$[28]$} \\
\hline & Pulau Besar, Melaka & 2.4 & 31.75 & [29] \\
\hline & Kuala Selangor, Selangor & 1.52 & 27.39 & [29] \\
\hline & Matang, Perak & 1.57 & 71.11 & [29] \\
\hline \multirow{9}{*}{ World's ocean } & Nuecas Bay, South Texas & $2.3-16.67$ & $2.5-43.3$ & {$[30]$} \\
\hline & Yeoja Bay, Korea & $1.5-4.8$ & n.d & {$[31]$} \\
\hline & Ulsan Bay, South Korea & $1.4-5.4$ & $4.49-19.9$ & {$[32]$} \\
\hline & Estuary Nakdong, Taiwan & $0.51-4.3$ & $1.2-16.2$ & {$[33]$} \\
\hline & Chao Phraya River, Bangkok & $2.1-4.3$ & $2.4-18.4$ & {$[34]$} \\
\hline & Bengal Bay, West India & $5.4-19.0$ & $3.0-7.6$ & {$[18]$} \\
\hline & South China Sea & 1.3 & 2.98 & {$[35]$} \\
\hline & Mississippi \& Atchafalaya, North America & $1.2-3.3$ & $0.7-7.4$ & {$[36]$} \\
\hline & Bengal Bay, West India & $2.0-19.0$ & $0.3-44.2$ & {$[37]$} \\
\hline
\end{tabular}

Note: *N.d is not determined. 


\section{Conclusions}

A radiochemical procedure was developed for the determination of Ra-isotopes in marine samples. Liquid scintillation counting combined with this procedure allows more rapids determination and much simply step to isolate radium isotope from an interference of other radionuclides. The present method found to be successfully and useful applied for the determination of radium isotopes in solid and liquid sample, and it could be applied to any matrix with appropriate modification. This procedure can preferentially be used for determination of very low level ${ }^{226} \mathrm{Ra}$ and ${ }^{228} \mathrm{Ra}$ in marine samples.

\section{Acknowledgements}

The authors would like to thank all individuals and organizations involved in this research, particularly the Universiti Kebangsaan Malaysia and Kapar Energy Ventures Sdn. Bhd. for their invaluable help. This research is funded by the Ministry of Science, Technology and Innovation, Malaysia (Science Fund grant No. 0401-02-SF0117).

\section{REFERENCES}

[1] M. J. Rodri'gez-Alvarez and F. Sa'nchez, "Measurement of Radium and Thorium Isotopes in Environmental Samples by Alpha-Spectrometry," Journal of Radioanalytical and Nuclear Chemistry, Vol. 191, No. 1, 1995, pp. 3-13. doi:10.1007/BF02035979

[2] M. T. Crespo, "On the Determination of ${ }^{226} \mathrm{Ra}$ in Environmental and Geological Samples by Alpha-Spectrometry Using ${ }^{225} \mathrm{Ra}$ as Yield Tracer," Applied Radiation Isotopes, Vol. 53, No. 1-2, 2000, pp. 109-114. doi:10.1016/S0969-8043(00)00120-2

[3] D. A. Clifford and E. A. Higgins, "Measurement of ${ }^{226} \mathrm{Ra}$ and ${ }^{228} \mathrm{Ra}$ in Water by Gamma-Ray Counting after Pre-Concentration on Ion-Exchange Resin," Health Physics, Vol. 62, No. 5, 1992, pp. 413-421. doi:10.1097/00004032-199205000-00005

[4] J. P. Bolívar, R. García-Tenorio and M. García-León, "Radioactive Impact of Some Phosphogypsum Piles in Soils and Salt Marshes Evaluated by Gamma-Ray Spectrometry," Applied Radiation Isotopes, Vol. 47, No. 9-10, 1996, pp. 1069-1075. doi:10.1016/S0969-8043(96)00108-X

[5] S. N. A. Tahir, K. Jamil, J. H. Zaidi, M. Arif, N. Ahmed and S. A. Ahmad, "Measurements of Activity Concentrations of Naturally Occurring Radionuclides in Soil Samples from Punjab Province of Pakistan and Assessment of Radiological Hazards," Radiation Protection Dosimetry, Vol. 113, No. 4, 2005, pp. 421-427.

doi:10.1093/rpd/nch484

[6] R. Blackburn and M. S. Al-Masri, "Determination of Radon-222 and Radium-226 in Water Samples by Cer- enkov Counting," Analyst, Vol. 118, No. 7, 1993, pp. 873 -876. doi:10.1039/an9931800873

[7] F. Scho"nhofer, "Measurement of ${ }^{226} \mathrm{Ra}$ in Water and ${ }^{222} \mathrm{Rn}$ in Water and Air by Liquid Scintillation Counting," Radiation Protection Dosimetry, Vol. 45, 1992, pp. 123125.

[8] H. Moreno, I. Vioque, G. Manjon and R. Garcia-Tenorio, "An Easy Method for Ra-226 Determination in River Waters by Liquid-Scintilation Counting Czech," Journal of Physics, Vol. 49, No. 1, 1999, pp. 467-472.

[9] S. Chalupnik and J. Lebecka, "Determination of Radium Isotopes in Liquids by Means of Quantulus Liquid Scintillation Spectrometer," Paper Presented at the 14th Europhysics Conference on Nuclear Physics, Bratislava Singapore, World Scientific, Vol. 327, 1990, pp. 327-336.

[10] S. Chalupnik and J. Lebecka, "Determination of ${ }^{226} \mathrm{Ra}$, ${ }^{228} \mathrm{Ra}$ and ${ }^{224} \mathrm{Ra}$ in Water and Aqueous Solutions by Liquid Scintillation Counting," Proceedings of Liquid Scintillation Conference on Radiocarbon, Vienna, 14-18 September 1992, pp. 397-403.

[11] K. Sato, T. Hashimoto, M. Noguchi, W. Nitta, H. Higuchi, N. Nishikawa and T. Sanada, "A Simple Method for Determination of ${ }^{226} \mathrm{Ra}$ in Environmental Samples by $\alpha-\beta$ Coincidence Liquid Scintillation Counting," Journal of Environmental Radioactivity, Vol. 48, No. 2, 2000, pp. 247-256. doi:10.1016/S0265-931X(99)00073-9

[12] Y. J. Kim, C. K. Kim and J. I. Lee, "Simultaneous Determination of ${ }^{226} \mathrm{Ra}$ and ${ }^{210} \mathrm{~Pb}$ in Groundwater and Soil Samples by Using Liquid Scintillation Counter-Suspension Gel," Journal of Radiation and Isotopes, Vol. 54, No. 2, 2001, pp. 275-281. doi:10.1016/S0969-8043(00)00190-1

[13] M. Villa, H. P. Moreno and G. Manjón, "Determination of ${ }^{226} \mathrm{Ra}$ and ${ }^{224} \mathrm{Ra}$ in Sediments Samples by Liquid Scintillation Counting," Journal of Radiation Measurement, Vol. 39, 2005, pp. 543-550.

[14] N. Antovic and N. Svrkota, "Measuring the Radium-226 Activity Using a Multidetector G-Ray Coincidence Spectrometer," Journal of Environmental Radioactivity, Vol. 100, No. 10, 2009, pp. 823-830. doi:10.1016/i.jenvrad.2009.06.003

[15] W. C. Lawrie, J. A. Desmond, D. Spence, S. Anderson and C. Edmondson, "Determination of Radium-226 in Environmental and Personal Monitoring Samples," Applied Radiation Isotopes, Vol. 53, No. 1-2, 2000, pp. 133-137. doi:10.1016/S0969-8043(00)00168-8

[16] G. J. Hancock and P. Martin, "Determination of Ra in Environmental Samples by $\alpha$-Spectrometry," Applied Radiation Isotopes, Vol. 42, No. 1, 1991, pp. 63-69. doi:10.1016/0883-2889(91)90125-K

[17] J. S. Alvarado, K. A. Orlamdini and M. D. Erickson, "Rapid Determination of Radium Isotopes by Alpha Spectrometry," Journal of Radioanalytical and Nuclear Chemistry, Vol. 194, No. 1, 1995, pp. 163-172. doi:10.1007/BF02037623

[18] S. Ghose, M. Alam and M. N. Islam, "Concentrations of 
${ }^{222} \mathrm{Rn},{ }^{226} \mathrm{Ra}$ and ${ }^{228} \mathrm{Ra}$ in Surface Seawater of the Bay of Bengal," Journal of Environmental Radioactivity, Vol. 47, No. 3, 2000, pp. 291-300. doi:10.1016/S0265-931X(99)00046-6

[19] J. Eikenberg, S. Bajo, H. Beer, J. Hitz, M. Ruethi, I. Zumsteg and P. Letessier, "Fast Methods for Determination of Anthropogenic Actinides and U/Th-Series Isotopes in Aqueous Samples," Applied Radiation Isotopes, Vol. 61, No. 2-3, 2004, pp. 101-106. doi:10.1016/j.apradiso.2004.03.020

[20] T. Hashimoto, K. Sato, Y. Yoneyama and N. Fukuyama, "Simultaneous Determination of Environmental Samples $\alpha$-Radionuclides Using Liquid Scintillation Counting Combined with Tome Interval Analysis (TIA) and Pulse Shape Discrimination (PSD)," Journal of Radioanalytical and Nuclear Chemistry, Vol. 222, No. 1-2, 1997, pp. 109-116. doi:10.1007/BF02034256

[21] H. Homma and Y. Murakami, "Study on the Applicability of the Integral Counting Method for Determination of ${ }^{226} \mathrm{Ra}$ in Various Sample Forms Using a Liquid Scintillation Counter," Journal of Radioanalytical Chemistry, Vol. 36, No. 1, 1977, pp. 173-184. doi:10.1007/BF02516265

[22] G. Manjón, I. Vioque, H. P. Moreno, , R. García-Tenorio and M. García-León, "Determination of ${ }^{226} \mathrm{Ra}$ and ${ }^{224} \mathrm{Ra}$ in Drinking Waters by Liquid Scintillation Counting," Applied Radiation Isotopes, Vol. 48, No. 4, 1997, pp. 535-540. doi:10.1016/S0969-8043(96)00297-7

[23] H. P. Moreno, A. Absi, I. Vioque, G. Manjón and R. García-Tenorio, "Application of a Liquid Scintillation Technique to the Measurement of ${ }^{226} \mathrm{Ra}$ and ${ }^{224} \mathrm{Ra}$ in Samples Affected by Nonnuclear Industries Wastes," Journal of Radioanalytical and Nuclear Chemistry, Vol. 245, No. 2, 2000, pp. 309-315. doi:10.1023/A:1006706320580

[24] J. M. Godoy, "Methods for Measuring Radium Isotopes: Gross Alpha Beta Counting. The Environmental Behavior of Radium," Vienna International Atomic Energy Agency, Vol. 1, 1990, pp. 205-212.

[25] G. Jia, G. Torri, P. Innocenzi, R. Ocone and A. Di Lullo, "Determination of Radium Isotopes in Mineral and Environmental Water Samples by Alpha-Spectrometry," Journal of Radioanalytical and Nuclear Chemistry, Vol. 267, No. 3, 2006, pp. 505-514. doi:10.1007/s10967-006-0079-8

[26] R. A. Tinker, J. D. Smith and M. B. Cooper, "An Assessment of Selection Criteria for an Analytical Method for Radium-226 in Environmental Samples," Journal of Radioanalytical and Nuclear Chemistry, Vol. 193, No. 2, 1995, pp. 173-176. doi:10.1007/BF02039890

[27] C. A. R. Mohamed, S. Y. Niow, M. A. Masni and A. Zaharudin, "Measurement Ratio of ${ }^{226} \mathrm{Ra} /{ }^{228} \mathrm{Ra}$ in Marine Samples Using the Cation Exchange Resin and Gross $\alpha / \beta$
Spectrometry," Asian Journal of Chemistry, Vol. 19, No. 2, 2007, pp. 1035-1044.

[28] S. Y. Nioo, Z. Ahmad and C. A. R. Mohamed, "Pencirian Aktiviti ${ }^{226} \mathrm{Ra}$ dan ${ }^{228} \mathrm{Ra}$ Dalam Sistem Sungai, Muara dan Marin di Malaysia," Thesis Master UKM, Malaysia, 2005.

[29] C. S. Phuah, Z. Ahmad and C. A. R. Mohamed, "Taburan Keaktifan Ra-226 dan Ra-228 Dalam Sistem Marin di Semenanjung Malaysia," Thesis Master UKM, Malaysia, 2001.

[30] J. A. Breier and H. N. Edmonds, "High ${ }^{226} \mathrm{Ra}$ and ${ }^{228} \mathrm{Ra}$ Activities in Nueces Bay, Texas Indicate Large Submarine Saline Discharge," Marine Chemistry, Vol. 103, No. 1-2, 2007, pp. 131-145. doi:10.1016/j.marchem.2006.06.015

[31] D. W. Hwang, G. Kim, Y. W. Lee and H. S. Yang, "Estimating Submarine Inputs of Groundwater and Nutrients to a Coastal Bay Using Radium Isotopes," Marine Chemistry, Vol. 96, No. 1-2, 2005, pp. 61-71. doi:10.1016/j.marchem.2004.11.002

[32] J. S. Lee, K. H. Kim and D. S. Moon "Radium in Ulsan Bay," Journal of Environmental Radioactivity, Vol. 82, No. 2, 2005, pp. 129-149. doi:10.1016/j.jenvrad.2004.11.005

[33] H. S. Yang, D. W. Hwang and G. Kim, "Factors Controlling Excess Radium in the Nakdong River Estuary, Korea: Submarine Groundwater Discharge versus Desorption Riverine Particles," Marine Chemistry, Vol. 78, No. 1, 2002, pp. 1-8. doi:10.1016/S0304-4203(02)00004-X

[34] Y. Nozaki, Y. Yamamoto, T. Manaka, H. Amakawa and A. Snidvongs, "Dissolved Barium and Radium Isotopes in Chao Phraya Estuarine Mixing Zone in Thailand," Continental Shelf Research, Vol. 21, No. 13-14, 2001, pp. 1435-1448. doi:10.1016/S0278-4343(01)00023-1

[35] Y. Nozaki and Y. Yamamoto, “228 Ra-Based Nitrate Fluxes in Eastern India Ocean and the South China Sea and a Silicon-Induced 'Alkalinity Pump' Hypothesis," Global Biogeochemical Cycles, Vol. 15, No. 3, 2001, pp. 555-567. doi:10.1029/2000GB001309

[36] J. M. Krest, W. S. Moore and Rama, ${ }^{6226} \mathrm{Ra}$ and ${ }^{228} \mathrm{Ra}$ in the Mixing Zones of Mississippi and Atchafalaya Rivers: Indicators of Groundwater Input," Marine Chemistry, Vol. 64, No. 3, 1999, pp. 129-152. doi:10.1016/S0304-4203(98)00070-X

[37] W. S. Moore, "High Fluxes of Radium and Barium from the Mouth of the Ganges Brahmaputra River during Low river Discharge Suggest Large Groundwater Source," Earth and Planetary Science Letters, Vol. 150, No. 1-2, 1997, pp. 141-150. doi:10.1016/S0012-821X(97)00083-6 